\title{
LA ESCULTURA ORNAMENTAL DEL PABELLÓN NACIONAL PORTUGUÉS EN LA EXPOSICIÓN IBEROAMERICANA
}

\author{
POR AMPARO GRACIANI GARCÍA
}

Sin duda alguna, de los pabellones internacionales levantados para la Exposición Iberoamericana de Sevilla de 1929, uno de los más interesantes fue el portugués, no sólo por la calidad estética y envergadura del edificio de este país, sino particularmente por las piezas escultóricas y la decoración pictórica que lo omamentaba. Posiblemente, a los profanos en la materia e incluso a los especialistas en la Muestra, esta afirmación resulte exagerada, en tanto en cuanto las noticias existentes sobre el pabellón eran muy limitadas y sólo se conservaban algunas fotografías de conjunto de éste, en las que apenas se evidenciaban detalles al respecto.

En nuestra Tesis Doctoral, defendida en el Departamento de Historia del Arte de la Universidad de Sevilla en mayo de 1993 bajo el título La participación internacional y colonial en la Exposición Iberoamericana: estudio históricoartístico, aportábamos una ingente cantidad de referencias sobre la decoración del pabellón portugués, que en este artículo intentaremos ofrecer en lo que respecta únicamente a la escultórica, noticias que fueron obtenidas de la prensa portuguesa de la época y, a partir de éstas, de la búsqueda en los museos de Lisboa y en la ornamentación urbana de la misma capital; de hecho, parte de la ornamentación escultórica de la que hasta la fecha nada se sabía se encuentra hoy dispersa por algunos museos locales y emplazamientos de Lisboa, aunque el destino de las restantes se ignora.

Ahora, una vez conocidas las piezas a través de la prensa del momento y de las revistas gráficas, es el momento de continuar la búsqueda que nosotros iniciamos en los museos por las colecciones privadas. No obstante, tampoco hay certeza de que estas piezas aún se conserven, considerando que el arte de esa época, como sucedió en nuestro país, estuvo muy desprestigiado durante años y sólo en las últimas décadas historiadores del Arte, encabezados por Auguste França, han reivindicado su valor. 
Desde que en marzo de 1928 se fallara el concurso de proyectos arquitectónicos para el pabellón, se observa en los medios artísticos de la capital un gran interés por preparar adecuadamente su decoración, especialmente la pictórica. Con argumentos nacionalistas, algunos críticos de arte expresaban la necesidad de realizar un esfuerzo al respecto. Así, el Doctor Sousa Costa en una conferencia que dió en el Salón de Bellas Artes de Lisboa bajo el título "A pintura portuguesa na Exposiçao de Sevilha", comentaba que había que:

"... prepararse bien para ir a Sevilla y hasta mejor que otros países justamente por ser más pequeño ya que a los pequeños nunca se perdona que se disculpen ante los grandes" 1 .

Según este crítico de arte y pintor, la decoración del pabellón había de evocar las diferentes regiones portuguesas. En su opinión, el Gobierno debía seguir el ejemplo de Mussolini quien había encargado a los artistas italianos pintar paisajes del país.

Desde abril y hasta diciembre, veinticuatro artistas nacionales, escogidos por el Comité Organizador de entre los mejores de la época y entre los cuales había escultores, pintores, ceramistas, yeseros y forjadores, instalaron su taller en el Palacio de Congresos de Lisboa. Allí trabajaron durante 1928, de modo que en diciembre de ese año las obras estaban muy adelantadas ${ }^{2}$ y los paneles decorativos, que ya se habían terminado, en espera de ser enviados a Sevilla ${ }^{3}$. De este modo, aprovechando la envergadura del Certamen, se pretendía incorporar al edificio un conjunto de obras que manifestasen el notable esfuerzo que el nuevo régimen político había implantado en Portugal en sólo dos años.

Aunque las fuentes de época dicen que de ellos siete eran escultores, nosotros tenemos referencia de ocho: Francisco Franco, Henrique Moreira, João da Silva, Rui Gameiro, Maximiano Alves, Antonio da Costa Mota (tío y sobrino) y César Barreiros. De los autores que trabajaron en la ornamentación pictórica del edificio, dejando a un lado los que expusieron sus pinturas en él, conocemos a los siguientes: Jorge Barradas, Abel Manta, Joaquim Lopes, Varela Aldemira, Martinho Gomes da Fonseca, Abel Martins, Benvido Ceia, Lino Antonio, Armando de Lucena, Leitão de Barros, José Joaquim Ramos, Vasco Lucena, Eduardo Romero y Martins Barata junto a su ayudante Batista. De modelar en yeso los pormenores ornamentales del

1. A PINTURA PORTUGUESA NA EXPOSIÇÃO DE SEVILHA, en $O$ Século de Lisboa, 27 de marzo de 1928 , p. 2.

2. O SR. MINISTRO DO COMERCIO EXAMINOU OS TRABALHOS PARA O PAVILHÃO PORTUGUES NA EXPOSIÇÃO DE SEVILHA, en $O$ Século de Lisboa, 6 de diciembre de 1928, p. 1; A MAQUETTE DO PAVILHÃO PORTUGUES NA EXPOSIÇÃO IBEROAMERICANA ESTARA EXPOSTO A PARTIR DE HOJE DURANTE OITO DIAS NUM ESTABELECIMENTO DO BAIXA', en $O$ Século de Lisboa, 8 de diciembre de 1928, p. 1.

3. A ARTE PORTUGUESA NA EXPOSIÇÃO IBEROAMERICANA, en $O$ Século de Lisboa, 6 de enero de 1929, p.1. 
pabellón se ocuparon los artistas José Maior y Manuel Joaquím Pinto ${ }^{4}$. Los ceramistas fueron Mario Reis, Alves de Sá y Leopoldo Battistini. Algunos de estos artistas, como João da Silva, Antonio María Ribeiro, Leopoldo Battistini y Viriato Silva,... también participaron en la Exposición Universal de Barcelona, donde Portugal estuvo representada en el Palacio de las Naciones Extranjeras ${ }^{5}$.

La ornamentación del pabellón fue encargo directo del Comité Organizador que, en unos casos, la encomendó a autores que ya habían trabajado en certámenes anteriores, a artistas de prestigio o a otros que -aunque no lo eran-por aquellas fechas habían expuesto sus trabajos en la Sociedad Nacional de Bellas Artes. Así Antonio Augusto da Costa Mota (sobrino) había tomado parte en las exposiciones de Panamá y del Centenario de Brasil, ocupándose de la decoración de los pabellones portugueses; entre los pintores en Río de Janeiro algunos habían sido premiados con correspondientes medallas, con la de plata, Luis Varela Aldemira y Joaquim Lopes y con la de oro Martinho Gomes da Fonseca. También participaron en la Iberoamericana nuevos artistas de la época como Martinho Gomes da Fonseca, Benvido Ceia, Leitão de Barros y Martins Barata; entre los que recientemente habían expuesto en los salones de la Sociedad Nacional de Bellas Artes, destacaban Eduardo Romero y José Joaquim Ramos.

Por su calidad e interés estilístico e iconográfico de las piezas, merece un detallado estudio la serie escultórica - bulto redondo y relieves- que ornamentó el pabellón portugués en la Exposición Iberoamericana. Desde el punto de vista temático se pueden establecer dos grandes grupos. La obras destinadas a la ornamentación de exteriores, jardines y patios menores del conjunto, las más abundantes en número, aludían a la epopeya descubridora y colonizadora de Portugal. Todos los escultores participantes, salvo César Barreiros, del que no existe obra escultórica documentada en los jardines, realizaron obras de este primer grupo. Por el contrario, en los interiores del pabellón, donde se prefirió la decoración pictórica, sólo se realizaron algunas piezas escultóricas para el Salón de Fiestas (Fig.1.) cuya temática guardaba estrecha relación con su destino. La fuente del patio principal no pasaba de ser una escultura de carácter ornamental.

El predominio de la escultura vinculada a los descubrimientos lusitanos, sin duda debida al propio carácter del Certamen, se produjo en unos momentos en que el nacionalismo hizo desarrollar la iconografía del héroe en la escultura portuguesa. Concretamente, a partir de la primera década del nuevo siglo se realizaban un sinfín de representaciones de personajes del pasado nacional: en unos casos jefes militares, pero muy especialmente descubridores como Alfonso de Alburquerque y grandes navegantes, entre ellos Vasco de Gama y Pedro Alvarez Cabral.

4. OS QUE TRABALHAM NO PAVILHÃO PORTUGUEZ DE SEVILHA, en O Noticias Ilustrado, 13 de enero de 1929, núm. 31, serie 2, p. 21.

5. A INICIATIVA PATRIOTICA DE O SECULO. VAI A SER ENVIADO PARA SEVILHA E BARCELONA O MATERIA DESTINADO A OS STANDS DA COMISSAO DE INICIATIVA DE O SECULO PARA PROPAGANDA DEL PAIS, en O Século de Lisboa, 13 de abril de 1929, p. 1. 


\section{ESCULTURAS DE HÉROES NACIONALES}

Cinco esculturas de cuerpo completo ornamentaban los jardines de pabellón, que en el mismo emplazamiento que ellos, venían a sustituir a los obeliscos diseñados por los hermanos Rebelo de Andrade en el proyecto arquitectónico original. Concretamente, fueron las de João Gonçalves Zarco, descubridor de las Madeira, Alfonso de Alburquerque, Virrey de la India, Vasco de Gama, el Infante Don Enrique el Navegante y Camões, autor de $O s$ Lusiadas, principal poema épico nacional. Mientras las restantes se dispersaban en los jardines que daban a la fachada principal del edificio, las de Alfonso de Alburquerque y Vasco de Gama se encontraban a las entradas a los patios de Oriente y Occidente, respectivamente (Fig.1).

Por otra parte, bustos de los grandes descubridores y caudillos portugueses decoraban los patios menores del pabellón que daban a la Avenida de Portugal.

\section{a. João Gonçalves Zarco (Francisco Franco) (Fig. 2)}

Sin duda, de todas ellas la de mayor trascendencia fue la que de João Gonçalves Zarco, descubridor de las Madeira (1418-19), realizó Francisco Franco (1885-). Era ésta la pieza principal de la exposición portuguesa, hasta tal punto que su presencia vino a mermar la atención prestada a las restantes obras. No tenemos certeza de su localización precisa; según algunas fuentes y como se desprende de las fotografías de la época, estuvo colocada al aire libre en la Avenida de Portugal, dando frente al pabellón ${ }^{6}$; en cambio, en los comentarios que José de Figueiredo hace sobre la participación escultórica portuguesa, el autor indica que la figura estuvo "fuera del recinto del pabellón pero en un sitio cerrado que los arquitectos procuraron que fuese el mejor posible" ?.

Esta fue la única escultura no realizada ex-profeso para el pabellón. Por el contrario, en Sevilla se expuso el original que Franco esculpiera para Funchal (Madeira) ${ }^{8}$ no una copia como en varias ocasiones se ha dicho y ya bien ha demostrado Joaquim Saial ${ }^{9}$. Aunque la idea de realizar la escultura se remontaba a diez años antes (1918) a propuesta del maderiense Manuel José Perestrelo Vieira, entonces Vicepresidente de la Junta de Distrito, y los trabajos preparatorios parecen datar de 1925 , se cree que la obra se realizó en 1928 , fecha de la que se conservan

6. RUIVO, Manuela M.: "El pabellón de Portugal en la Exposición Iberoamericana de 1929", Revista Aparejadores, $\mathrm{n}^{\circ} 26$, junio de 1988.

7. Diário de Noticias de Lisboa, 27 de mayo de 1929, p. 1

8. El monumento no fue inaugurado en Funchal hasta finales de mayo de 1934. (Vid.: GONÇALVES ZARCO: A INAUGURAÇAO DA ESTATUA AO GLORIOSO DESCOBRIDOR DA MADEIRA, en Diário de Noticias de Lisboa, 1 de junio de 1934, p.1.)

9. FRANÇA, José Augusto: A Arte em Portugal no século XX, Bertrand, Lisboa, 1990 (3a. ed.); SAIAL, Joaquim: Estatuaria portuguesa dos anos 30 (1926-1940) . Ed. Bertrand. Losboa, 1992. , p. 209. 
las primeras fotografías del modelo inicial ${ }^{10}$. Cabría preguntarse, ¿Por qué precisamente se escogió esta obra y no otra?.

Sin duda ello se debió a la calidad de la pieza, que fue considerada en la época "una de las mejores esculturas que en mucho tiempo se habia hecho en Portugal"ll, por su "magistral ejecución" y la "viva sensibilidad de su modelado" 12 . Pero además, en opinión de los críticos de arte y articulistas de prensa (Diário de Noticias, Seara Nova...), el Zarco de Franco se había convertido en todo un símbolo de la nueva escultura nacional; una pieza sobria y sencilla y al mismo tiempo sintética por servir de transición entre los modelos decimonónicos y el moderno panorama escultórico europeo que, en la línea de Rodin, Bourdelle, Despiau, Maillol y Bernard, se presentaba libre de los excesos literarios y declamatorios del siglo XIX. En opinión del crítico Manuel Méndes la escultura era "digno representante de la escultura modema" ${ }^{13}$. La novedad del Zarco era su vigorisidad y fuerza anímica, la ausencia de esa torpe retórica de la escultura pública del siglo anterior; por su arrogancia, la figura se vió como una expresión del carácter nacional, "valiente, consciente y facundo" ${ }^{14}$, que podría ser el de cualquier héroe portugués, Vasco de Gama, Magallanes o Alburquerque ${ }^{15}$. Por ello, comparando la escultura con la producción pictórica de Nuno-Gonçalves, repetidamente se la calificó como nunogonçalvesca. Como diría Figueiredo:

"Su autor supo extraer de las pinturas de Nuno Gonçalves todo el ensimismamiento que ellas contenían, $y$, por eso, a su obra, por el poder expresivo que revela y por la valiente síntesis con que fue realizada, es antigua y es moderna, lo que quiere decir que esta escultura es una buena escultura ${ }^{16 "}$.

Además, dentro de la producción del autor era muy diferente de lo que hasta el momento había realizado; pese a su arrogante postura y semblante tenía ya el naturalismo clásico y tranquilo así como la combinación de sobriedad y detallismo de ejecución que se convertirían en rasgos característicos del escultor, careciendo por el contrario de ese expresionismo tan realista de otro monumento a Gonçalves Zarco que, también para Funchal, Franco hiciera en $1919^{17}$.

De este modo la presencia en Sevilla de la escultura se hacía inevitable sobre todo considerando que a finales de la década de los veinte Francisco Franco y Leopoldo de Almeida se habían convertido en los artistas más solicitados en los

10. AMARO, Carlos: "O Escultor Francisco Franco", en llustraçao de Lisboa, núm. 52, 16 de febrero de 1928, p. 1.

11. FIGUEIREDO, José:... en Diário de Noticias de Lisboa, 27 de mayo de 1929, p. 1.

12. AMARO, Carlos: Op. cit., p. 1.

13. A ESTATUA DE GONÇALVES ZARCO, en Diário de Noticias de Lisboa, 29 de octubre de 1928, p. 2.

14. MENDES, Manuel: "Francisco Franco", en Seara Nova de Lisboa, núm. 34, 25 de octubre de 1928, p. 273.

15. AMARO, Carlos: Op. cit., p. 1.

16. Diário de Noticias de Lisboa, 27 de mayo de 1929, p. 1.

17. Realizado para un cementerio local en memoria de las víctimas del bombardeo alemán de 1918. 
encargos oficiales, llegando Franco a ser, especialmente tras la Exposición Colonial de París, el principal estatuario del régimen.

Una vez más, la iniciativa de que la obra de Franco figurase en la Muestra Iberoamericana partió del Diário de Noticias de Lisboa. Así lo recoge Saial. En primera página el periódico publicó esta sugerencia, que había aportado un madeirense, concretamente, el 5 de noviembre, durante los doce días en que antes de ser embarcada para Madeira, desde desde el 27 de octubre al 7 de noviembre de $1928{ }^{18}$, "para que todos la viesen y criticasen" la escultura estuvo expuesta al público en la Avenida de la Libertad de Lisboa, frente a la calle Rosa Araujo ${ }^{19}$. La propuesta fue seguida dos días más tarde por el escritor Sousa Costa, reincidiendo en ella el día 8 un tal Eurico Sena Cardoso.

No obstante, sus pareceres y los de otras muchas personalidades no encontraron de inmediato el eco necesario, por lo que, una vez retirada de la avenida, el 10 de noviembre la pieza partió para su destino, Funchal (Madeira), a bordo del vapor Funchalense $^{20}$. El día 20, en el Diário de Noticias de apelaba a las autoridades de Funchal $^{21}$; un mes más tarde, el 21 de diciembre, dicho periódico reveló la posibilidad de que este llamamiento pudiera llegar a ser atendido ${ }^{22}$.

La propuesta había tenido su repercusión en Madeira donde la Junta General aceptó la idea en espera de que el Comisario General de Portugal en la Exposición, Feliciano Soares ${ }^{23}$, lo aprobara, garantizando la seguridad en el transporte a Sevilla y la conservación de la pieza. Tras las pertinentes gestiones, Soares consiguió que a finales de mayo, una vez la inaugurado el Certamen Iberoamericano, el Gonçalves Zarco de Franco estuviera expuesto en Sevilla. No obstante, la escultura se exhibió sin el pedestal que, con bajorrelieves alegóricos, para ella había diseñado el arquitecto Cristino da Silva ${ }^{24}$.

18. Diário de Noticias de Lisboa, 27 de octubre de 1928, p. 1 y $O$ Século de Lisboa, 27 de octubre de 1928, p. 1. También hay referencias en la prensa del día siguiente.

19. A ESTATUA DE GONÇALVES ZARCO FOI DESDE ONTEM EXPOSTA, AO AR LIVRE, NA AVENIDA DA LIBERDADE, en $O$ Século de Lisboa, 28 de octubre de 1928, p. 1.

20. En principio estaba previsto que el día 8 la escultura partiera para Funchal a bordo del Lima. (Vid.: GONÇALVES ZARCO, en $O$ Século de Lisboa, 9 de noviembre de 1928, p. 1.)

21. Diário de Noticias de Lisboa, 20 de noviembre de 1928, p. 1.

22. Diário de Noticias de Lisboa, 27 de mayo de 1929, p. 1.

23. Ruivo (op. cit., p.16) comenta que Soares consiguió que la Junta General del Distrito de Funchal aceptara el requierimiento de Feliciano Soares, Comisario portugués en la Exposición, de mandar la escultura de Zarco.

Erróneamente la autora dice que la escultura de Zarco la realizó Francisco Santos.

24. MACEDO, Diego de: "Monumento a Gonçalves Zarco," en Ilustraçao Moderna, núm. 27, noviembre de 1928, p. 198.

En su artículo, el autor recoge el proyecto original del monumento; cita cuatro relieves y un escudo en la base, que jamás se realizaron y posteriormente fueron cambiados por otros. En el frontal, se situaría la representación de la Lusitania; en los laterales, La Fuerza y La Ciencia. Al principio, en la parte posterior, en vez de una alegoría estaba el Infante Don Enrique, a cuya casa Zarco pertenecía, con un sombrero borgoñés en la cabeza y una carta de navegación en la mano. Bajo la figura de la Lusitania 


\section{b. EI Infante Don Enrique el Navegante (Antonio da Costa Mota, sobrino) y Camões (Antonio da Costa Mota, tío)}

Dos esculturas sedentes se dispusieron en los jardines del pabellón ante la Glorieta de San Diego: frente a la Galería de Administración, una de Antonio de Costa Mota (sobrino) representando a Don Enrique el Navegante y otra de Camões de Antonio de Costa Mota (tío) emplazada delante de la Galería de Turismo.

Hasta la fecha la escultura de Camões -muy en la línea novecentista- ${ }^{25}$ había sido considerada de autoría incierta, aunque equivocadamente Saial la atribuía a Maximiano Alves, al considerarla una de las "dos estatuas de simbolismo histórico" que la bibliografía refería que el escultor realizó para el pabellón ${ }^{26}$. La prensa de la época confirma un hecho que, por la simple observación de las diferencias estilísticas, parecía evidente: que la obra no se debía a Maximiano Alves y que la fuente aludida se refería a las esculturas de Alfonso de Alburquerque y Vasco de Gama que Alves esculpió para las entradas de los patios de los navegantes, dando a la Avenida de Portugal, y que hoy se encuentran en el Museo de la Marina de Belém ${ }^{27}$.

Las estatuas de Camões y el Infante Don Enrique el Navegante simbolizaban los dos factores que fueron imprescindibles para los descubrimientos portugueses: el apoyo político y económico de la Monarquía, personificado con el Infante Don Enrique el Navegante y el empuje del espíritu aventurero portugués, representado por Camões ${ }^{28}$. La presencia de ambas figuras originó una gran polémica. A principios de abril, cuando aún no se había determinado si la escultura de Gonçalves Zarco estaría en Sevilla, en los medios periodísticos portugueses se planteó la cuestión de cuál debía de ser el motivo iconográfico que había de presidir el pabellón. Surgieron estas dos posibilidades.

se encontraba también un blasón de los Zarcos de Cámara, después sustituido por el escudo nacional. Sobre la obra definitiva, vid.: MACEDO, Diego de: "Subsídios para Uma Análise à Obra de Francisco Franco", en Belas- Artes, núm. 6, 1953, p. 5.

25. UNA ESTATUA DE CAMÕES EM SEVILHA, en $O$ Século de Lisboa, 16 de agosto de 1928, p. 9. 26. SAIAL, J.: Op. cit., p. 268. El autor se basa en la entrada ALVES, Maximiano, en Grande Enciclopédia Portuguesa e Brasileira. Lisboa, 1945, tomo 2, p. 221.

27. El error de Saial parece incomprensible pues resulta extraño que el autor no haya apreciado que estas dos esculturas, idénticas en material, dimensiones, estilo incluso en posición sean obra de un mismo autor y tuvieran el mismo destino, sobre todo teniendo en cuenta que conocía que Alves había realizado dos piezas para Sevilla.

28. Durante la semana portuguesa que se inauguró el 1 de octubre uno de los días estuvo dedicado a Camões.

SEMANA DE PORTUGAL, en El Liberal de Sevilla, 27 de septiembre de 1929, p. 4; LA SEMANA DE PORTUGAL, en El Noticiero Sevillano, 6 de octubre de 1929, p.1.; LA EXPOSICION IBEROAMERICANA. LA SEMANA DE PORTUGAL, en El Liberal de Sevilla, 5 de octubre de 1929, p. 6.; EXPOSICION IBEROAMERICANA. LA SEMANA DE PORTUGAL, en El Liberal de Sevilla, 6 de octubre de 1929, p. 1; LA SEMANA DE PORTUGAL, en El Liberal de Sevilla, 8 de octubre de 1929, p. 5; EL DIA DE CAMÕES EN EL PABELLON DE PORTUGAL, en El Liberal de Sevilla, 12 de junio de 1929 , p. 1. 
Los orígenes de la polémica estaban en la propuesta de Antonio Ferro de colocar una estatua del Infante Don Enrique el Navegante en una placita situada al fondo de la Avenida de Portugal y que serviría como rotonda de circunvalación a los vehículos que circularan por dicha avenida. Para ello, Ferro contaba con el apoyo anticipado del Presidente de la República, el Cardenal Patriarca, el Comisario Portugués en la Exposición de Sevilla, el coronel Silveira y Castro y Gago Coutinho. Con gran entusiasmo y cayendo en una excesiva exageración, Ferro argumentaba que:

"una Exposición Iberoamericana sin un monumento al Infante Don Enrique sería lo mismo que una Catedral donde faltase un altar mayor" ${ }^{29}$.

En esas fechas, no existía en Portugal monumento público alguno destinado al Infante Don Enrique pues la columna rostral que a finales del siglo anterior (1883) se había proyectado en su honor en Sagres nunca había llegado a realizarse ${ }^{30}$. Por ello, la idea de Ferro fue inmediatamente aplaudida por la prensa portuguesa, concretamente por "A Voz" y "O Rebate". Sin embargo no encontró el apoyo del "Diário de Lisboa", cuyo director opinaba que la estatua debía de ser de Camões ${ }^{31}$.

Pese al importante papel que el Diário de Noticias de Lisboa ejerció en todo lo referente a la participación portuguesa en el Certamen hispalense, finalmente prevaleció la idea de Ferro y para Sevilla fue una estatua del Infante realizada por Antonio Augusto de Costa Mota (1877-?), sobrino del afamado escultor Costa Mota con quien había colaborado. No era la primera experiencia exposicional del autor quien, desde su vuelta de París, había trabajado en la decoración de los pabellones portugueses en las muestras de Panamá y Río de Janeiro. Sus relaciones con el Gobierno hacían inevitable su presencia en Sevilla, sobre todo si tenemos en cuenta que formó parte del jurado del concurso de proyectos arquitectónicos del pabellón. Finalmente, la decisión de enviar a Sevilla el Gonçalves Zarco de Francisco Franco motivó que se mandara a Sevilla no sólo una escultura del Infante sino también otra de Camões, realizada por Antonio da Costa Mota, tío, y que ambas fueran emplazadas presidiendo el pabellón, donde los Rebelo de Andrade habían proyectado sendos obeliscos decorativos.

Aunque ignoramos el destino de la escultura de Camões que para Sevilla realizara Costa Mota, conocemos cómo era por una única imagen fotográfica que aparece en la prensa nacional ${ }^{32}$. Por el contrario, la reproducción que también en $O$ Século de Lisboa existe de la escultura del Infante Don Enrique nos ha permitido

29. Diário de Noticias de Lisboa, 1 de abril de 1928, p. 1.

30. En 1928 el escultor Simoes de Almeida (sobrino) realizó una escultura del Infante para ese monumento frustrado, que ya no respondía al esquema inicial y que terminó en Vila Franca do Campo (San Miguel, Azores) con motivo de las fiestas conmemorativas del Quinto Centenario del descubrimiento de las islas.

31. Referencias al respecto pueden encontrarse en la prensa de los días siguientes al 1 de abril de 1928.

32. A ESCULTURA PORTUGUESA EM SEVILHA. DON HENRIQUE, en $O$ Século de Lisboa, 11 de agosto de 1928, p. 4. 
localizarla en una plaza de Lisboa. La figura aparecía representada con un sombrero borgoñés y la carta de navegación en la mano. En opinión de Saial la figura no llegó a alcanzar el interés de la que, con el mismo tema en 1931 Franco hiciera para el pabellón portugués en la Exposición Colonial de París. No obstante, resulta evidente que presentaba mayor calidad estética que la de Camões.

\section{c. Alfonso de Alburquerque y Vasco de Gama (Maximiano Alves) (Museo de la Marina, Lisboa) (Fig.3)}

Hasta la fecha, sólo una de estas esculturas, concretamente la de Alfonso de Alburquerque, estaba documentada como obra de Maximiano Alves (1888-1954) ${ }^{33}$. Ambas se exponen hoy en el Museo de la Marina de Lisboa. Aunque estilísticamente estan muy próximas a Costa Mota (tío) ya que, como bien señala Saial, el Alburquerque guarda gran parecido con una obra de este mismo tema que en el siglo anterior realizara este autor, la arrogante postura, con una pierna adelantada, y la expresividad y fuerza anímica que presentan ambas figuras, Vasco de Gama y Alburquerque, nos permite calificarlas de "nunogonçalvescas".

Las piezas no aportan novedades iconográficas. Alves representa a Alburquerque (Fig. 3) del modo tradicional, con el gorro y la casaca de época, apoyado en su espada, de forma muy similar a como, años más tarde, en 1940, hiciera en una obra que con el mismo tema para Nova Goa, en la India, aunque la de Sevilla presenta una postura mucho más arrogante ${ }^{34}$. El interés de esta figura es que dió pie a una fase en que se convirtió en motivo iconográfico muy usual, especialmente en acontecimientos exposicionales; de hecho, a ella sucederán otras como las que Diego de Macedo esculpiera para las Exposiciones Colonial de París y Oporto en 1931 y 1934, respectivamente ${ }^{35}$.

\section{d. Bustos}

Los patios menores del pabellón que daban a la Avenida de Portugal, llamados de Oriente y Occidente, cuyas entradas estaban precedidas, respectivamente, por las esculturas de Alfonso de Alburquerque y Vasco de Gama, se ornamentaban con ocho bustos de caudillos y navegantes portugueses. Sobre pilastras en forma de estípites, los bustos quedaban adosados dos a dos a los muros Este y Oeste de dichos patios; alcanzaban así la altura de los salmeres de las arcadas que los conformaban.

\section{Ut supra.}

34. SAIAL, J.: Op. cit., p. 73 y nota 116. El autor recoge que en octubre de 1940 (Occidente, núm. 30 octubre de 1940, p. 133) Diego de Macedo anunciaba el envío de una escultura de Alburquerque para la India (Nova Goa). La única imagen que de ella se conserva es una fotografía que el autor supone ser no de la pieza ejecutada sino de la maqueta previa.

35. La de Oporto quedó tras la muestra en las inmediaciones del Palacio de Cristal, desde donde posteriormente se trasladó a la Plaza de D. Juan III, cuyo centro hoy ocupa. 
En el patio de Oriente, se dispusieron los bustos de Fernando de Magallanes, Corte Real, Pedro Alvarez Cabral y Duarte Pacheco, de los cuales desconocemos sus autores. En el occidental, estaban los de Gil Eanes, Gonçalves Zarco, Diego Cao y Bartolomé Díaz. Pocas noticias hay sobre la autoría de los bustos; tan sólo sabemos, gracias a unas fotografías de la época, que el de Gonçalves Zarco se encargó al consagrado ártista Antonio Da Costa y el de Bartolomé Díaz al hijo del maestro Roque Gameiro, el joven escultor Rui Roque Gameiro (1907-1935), quien por aquellas fechas se ocupaba de realizar el Monumento a la Patria (o a los Muertos en la Gran Guerra) de Abrantes ${ }^{36}$.

Las dos fotografías que de los bustos de Bartolomé Días (de Rui Roque Gameiro) (Fig. 4) y João Gonçalves Zarco aparecieron en la revista ilustrada del Diário de Noticias (O Noticias Ilustrado) de Lisboa ${ }^{37}$, nos han permitido identificar los bustos con ocho existentes en el Museo de la Ciudad de Lisboa, hasta el momento de origen desconocido (Fig. 5). La serie de bustos, no sólo los de Zarco y Bartolomé Díaz como indica Saial, eran ya zarquistas, pues dejaban clara la huella de la obra de Franco. Se convirtieron, por tanto, en las primeras piezas de una larga serie que iría a proliferar en los decenios siguientes.

\section{OTROS TEMAS}

En menor número y, probablemente, de menos calidad e interés por las escasas referencias documentales existentes al respecto, otras piezas escultóricas debieron decorar las principales salas del conjunto.

Sabemos que César Barreiros realizó en un único bloque de madera dos bustos de Beethoven y de Antero simbolizando "la más alta inspiración" ${ }^{38}$. Aunque se ignora su destino preciso, por el tema es de suponer que se realizaron para el Salón de Fiestas.

Para esta misma sala, el escultor Henrique Moreira (1890-?) realizó cuatro bajorrelieves representando las distintas danzas nacionales: Aveiro, Ribatejo, Alentejo y Minho (Fig. 6). Sólo se conservan fotografías de tres de ellos ${ }^{39}$. Todos tenían en común el ser composiciones realizadas en base a tres personajes populares, ataviados con sus vestimentas regionales típicas: dos mujeres que, animadamente

36. Aunque concebido en agosto de 1928 , este monumento no se inauguró hasta 1940 , ya fallecido el artista que murió trágicamente junto a su esposa en un accidente de aviación en 1935.

37. OS QUE TRABALHAM NO PAVILHÃO PORTUGUEZ DE SEVILHA, en O Noticias Ilustrado, 13 de enero de 1929, núm. 31, serie 2, p. 21.

38. ACTUALIDADES, en $O$ Noticias Ilustrado de Lisboa, 4 de noviembre de 1928, núm. 21, Serie II, p. 5.

Por aquellas fechas César Barreiros realizaba una imagen de la Virgen de Fátima en madera policromada, un busto de Camilo Castelo Branco, adquirido por el Museo de San Miguel de Selde y un busto de Miguel Luis Borjao (VIDA ARTISTICA. A SENHORA DE FATIMA, SEGUNDO A CONCEPÇÃO ARTISTICA DO ESCULTOR Sr. CESAR BARREIROS, en $O$ Século de Lisboa, 27 de julio de 1928, p. 4.)

39. SAIAL, J.: Op. cit., p. 209. 
bailan, palmean y danzan en torno a un personaje masculino que, en posición más o menos hierática, les sirve como eje.

Moreira supo lograr una sensación de profundidad a estas obras, tan pintorescas y al mismo tiempo naturalistas. Para ello combinó distintos tipos de relieve (desde los planistas fondos de follaje vegetal, a los más marcados de las figuras); con objeto de dar cierta espacialidad a las escenas, unió a los protagonistas entre sí, cruzando su piernas en distintos planos, teniendo como referencia los dos cestos que enmarcan cada una de las composiciones. Diluyendo gradualmente el relieve de las plantas que estos contenían, logró una paulatina fusión con el fondo vegetal de la composición. En conjunto, habría que destacar el optimismo realista y festivo que, tan de acuerdo con la finalidad de la sala, Moreira incorporó a su obra.

Una de las obras más significativas de las instalaciones era la fuente de cuatro surtidores existente en el patio principal del pabellón que, llamada de la Juventud, fue realizada por el gran escultor, medallista y cincelador João da Silva (1880-1963) (Fig. 7). Da Silva, consagrado como escultor en Suiza y Francia, adquiría gran fama en esas fechas en Portugal donde acababa de realizar los monumentos a Julio Diniz y el de Pouliguen a los Muertos en la Gran Guerra, obras de tema popular nacional (Campesino de Ribatejo, Zagais, Alentejanos) y varias series de animales (Cabritos y Patos).

Desmontada la parte provisional del pabellón, la Fuente de la Juventud pasó al Parque de Eduardo VII, donde la figura de la cabra que coronaba el conjunto fue robada. Los desperfectos que allí sufrió motivaron su traslado al Museo de la Ciudad de Lisboa, en cuyos fondos se encuentran los elementos que de ella quedan, aunque en mal estado de conservación.

Conocemos su composición gracias a algunas fotografías de la época ${ }^{40}$. El conjunto estaba constituído por tres motivos: un niño (Fig. 8) que recogía el agua que caía de la cima, una figura femenina que la esquivaba y una cabra que seguía la escena montada en lo alto de un pilón central. Las volutas de la taza imitaban ondas y se confundían con el agua. No existiendo una relación temática entre las dos figuras humanas y el animal que remata el conjunto, todo hace suponer que da Silva quiso mostrar sus dotes animalísticas, eligiendo precisamente un motivo que ya había sido tratado por él en numerosas ocasiones anteriores y que repetirá constantemente en aquellas fechas. Pensemos que da Silva fue uno de los artistas portugueses que en la muestra Internacional de Barcelona de 1929 expuso en la Sección de Escultura de la Exposición Internacional de Pintura, Escultura, Dibujo y Grabado, organizada por la Dirección General de Bellas Artes y que en ella participó con el grupo Pastor y cabritos que le mereció la medalla de plata.

Las figuras de la fuente estaban tratadas con la gracia, finura expresiva y, pese a la asimetría del conjunto, un equilibrio compositivo característicos del artista. Destacaba en ella su gran naturalismo basado en una escrupulosa observación del modelo, aunque sin llegar al realismo puesto que da Silva buscaba la esbeltez de las formas y la armonía

40. O NOSSO ESFORÇO EM SEVILHA, en O Noticias Ilustrado, 26 de mayo de 1929, núm. 50, serie II, pp. 4 y 5. 
de la composición clásica. En la fuente, donde todos los elementos aparecían en movimiento, se evidenciaba ese gusto del escultor por lo dinámico, pretendiendo, junto al naturalismo físico de las actitudes de sus figuras, el psíquico: la posición de la mujer y el niño reflejaba no sólo el instante momentáneo sino también la sorpresa e imprensión que causaba en ellos el agua que caía desde la cumbre.

Según Saial, aunque no se pueda decir que hubiera en esta fuente rasgos de novedad o de imaginación, se evidenciaban en ella al menos las buenas cualidades como modelador de Juan de Silva, sobre todo en su faceta como animalista. En opinión del historiador, a pesar de sus excesos decorativos protobarrocos, o tal vez por eso mismo, esta fuente presentaba la dignidad necesaria para poderse integrar en la obra joanina de los Rebelo de Andrade ${ }^{4 !}$.

Teniendo en cuenta que en el taller del escultor, conservado gracias a la metódica labor y al cariño de su hija Gabriela da Silva y de su colaborador el Dr. José Mantas, existen dos figuras de la cabra perdida, una en bronce y otra en escayola, la fuente debería reconstituirse reproduciendo el animal perdido ${ }^{42}$.

41. SAIAL, J.: Op. cit., pp. 186-188.

42. Esta información y las imágenes que aportamos en nuestra Tesis Doctoral y de las cuales algunas reproducimos aquí, las obtuvimos por gentileza de Gabriela da Silva y el Dr. José Mantas y de la prensa local portuguesa. 


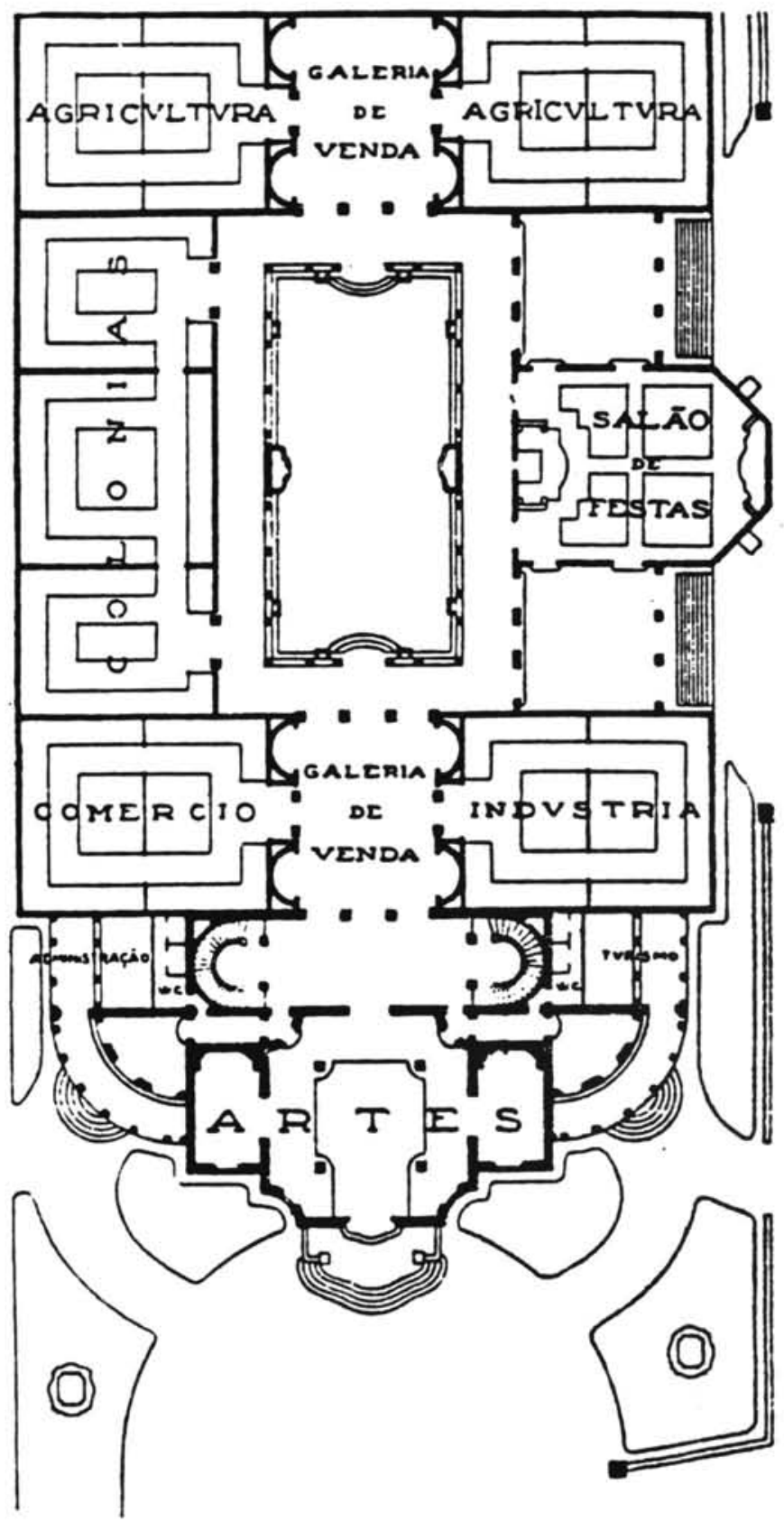

Fig. 1.

Plano de planta del pabellón de Portugal (OS INDUSTRIAIS DO NOSSO PAIS E AS INDUSTRIAIS DOS PAIS VISINHO, en Revista Industria Portuguesa, año 2, núm. 18, agosto de 1929, p. 31). 


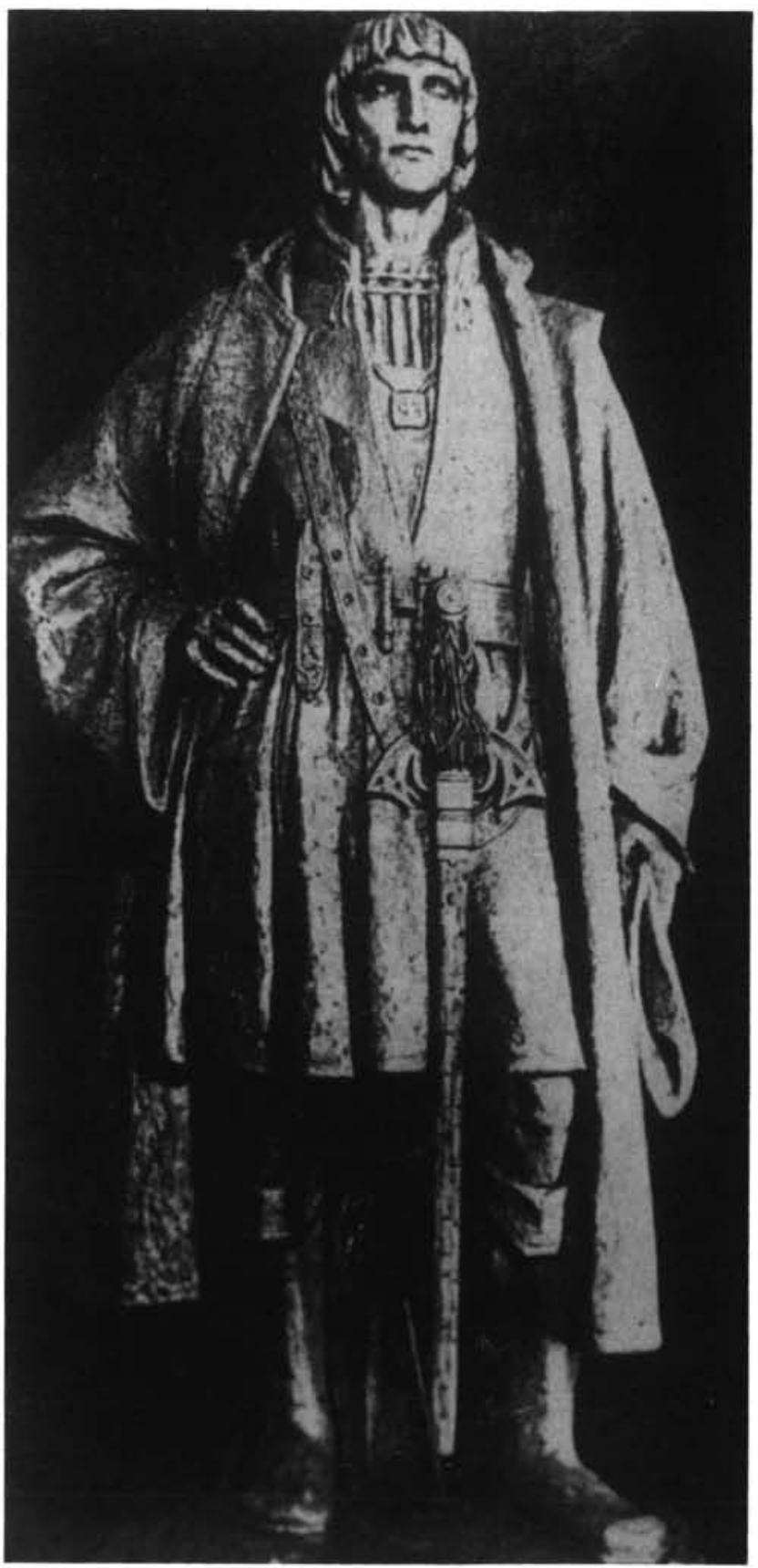

Fig. 2.

Escultura de Joao Gonçãlves Zarco, descubridor de las Islas Madeira, obra de Francisco Franco. 


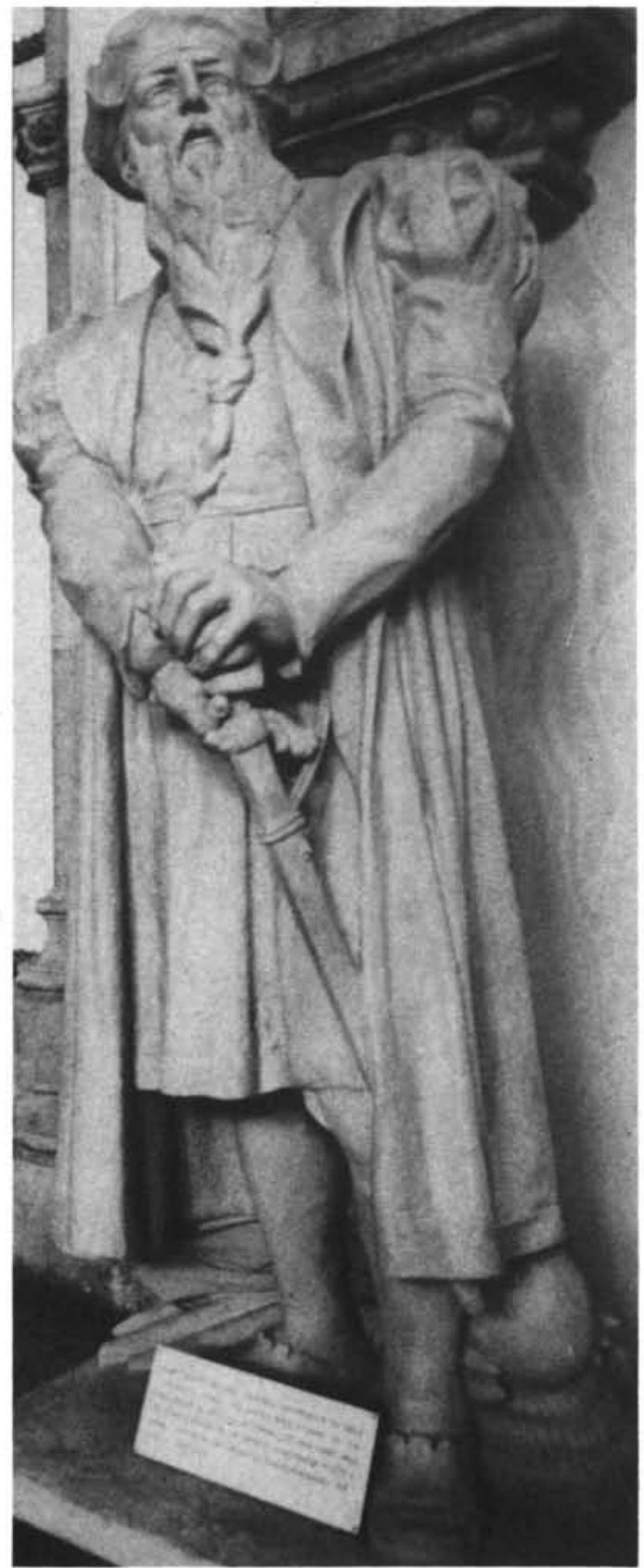

Fig. 3.

Escultura de Alfonso de Alburquerque, obra de Maximiano Alves (Museo de la Marina de Lisboa). 


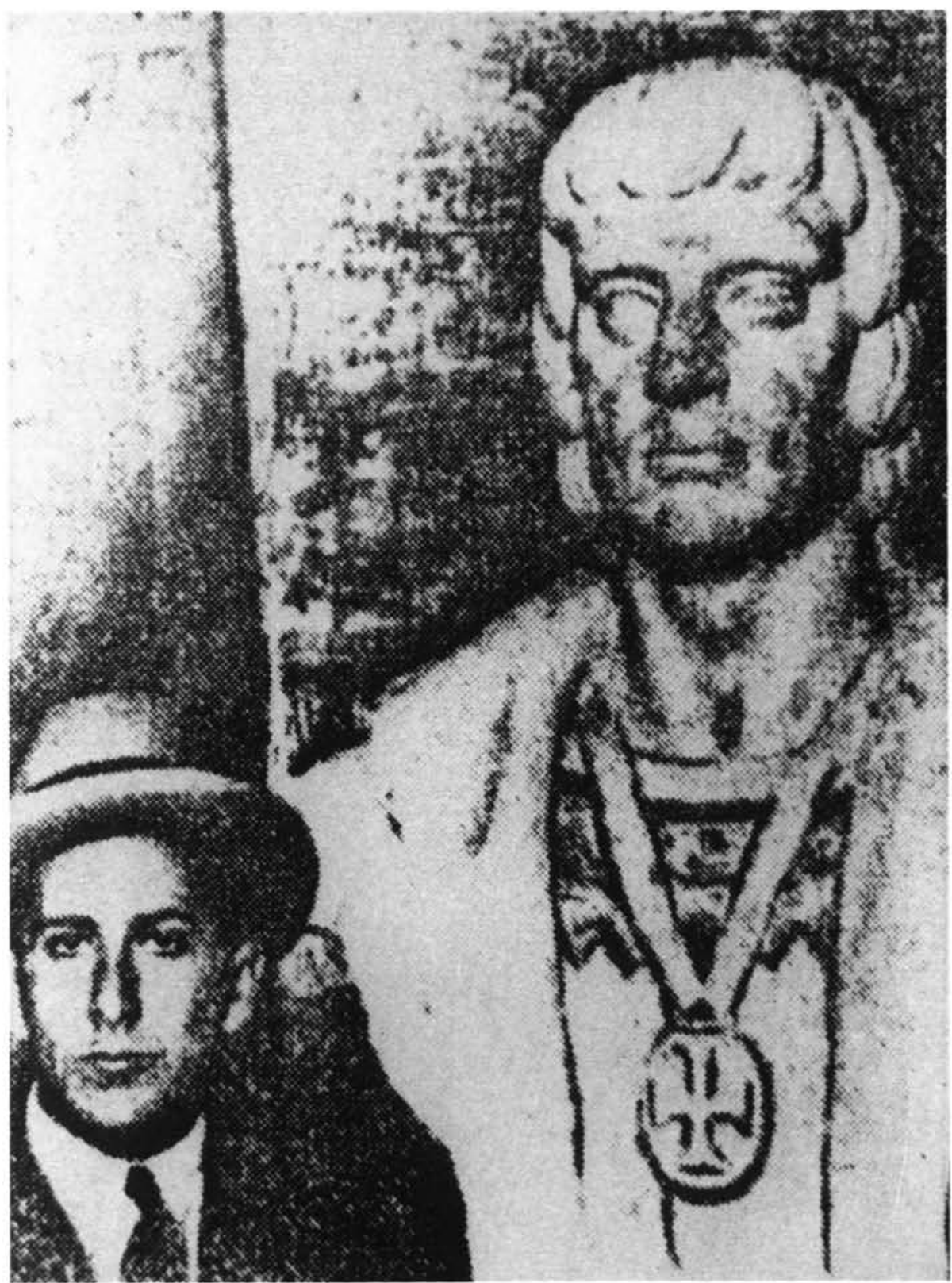

Fig. 4.

Rui Roque Gameiro con el busto de Bartolomé Diaz, por él realizado (OS QUE TRABALHAM NO PAVILHAO PORTUGUEZ DE SEVILHA, en $O$ Noticias Ilustrado de Lisboa, $\mathrm{n}^{\circ} 3$, serie III, 13 de enero de 1929, p. 2.). 


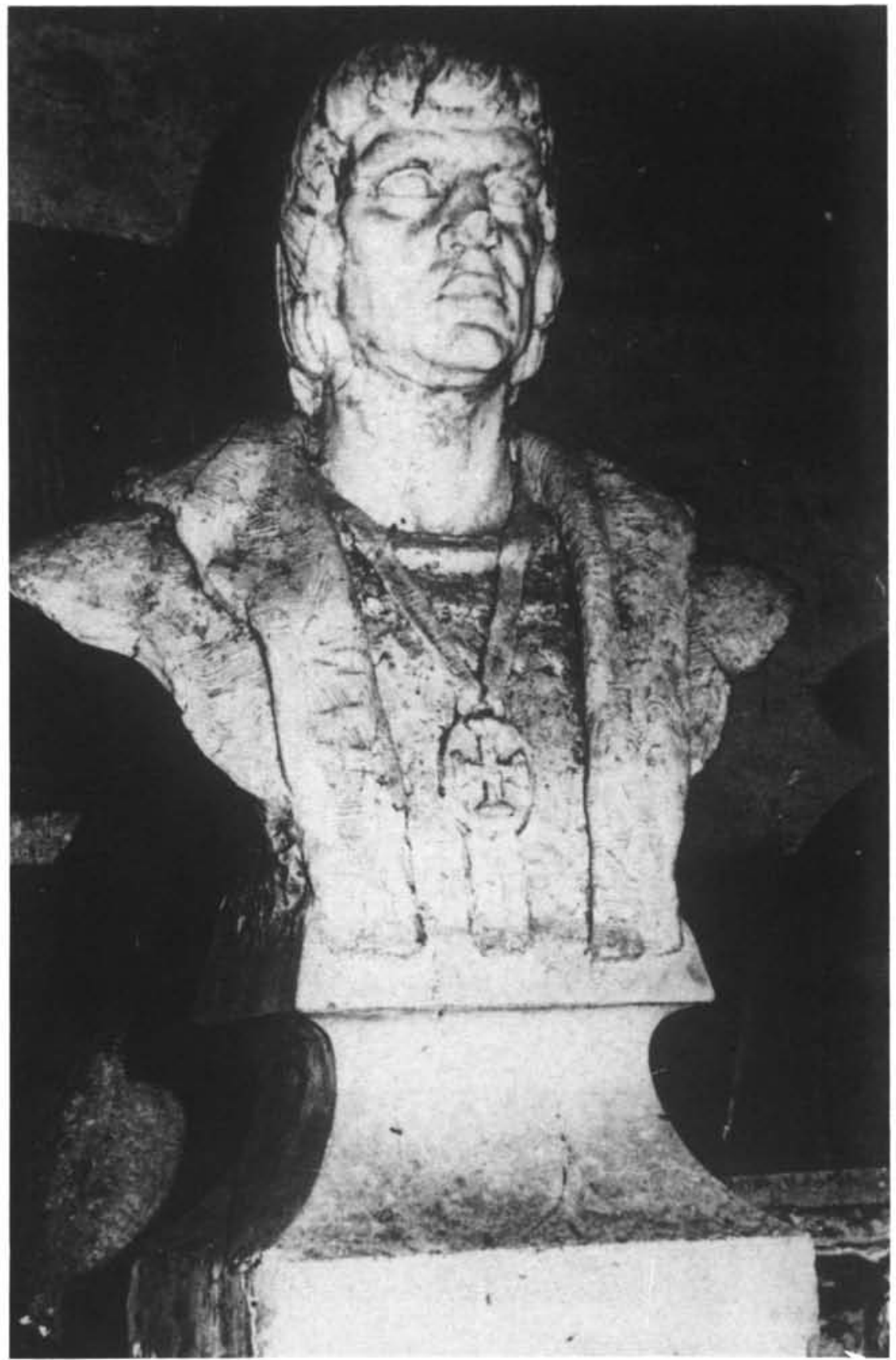

Fig. 5.

Busto de Bartolomé Díaz, obra de Rui Roque Gameiro para el patio occidental del pabellón (Fondos del Museo de la Ciudad de Lisboa). 


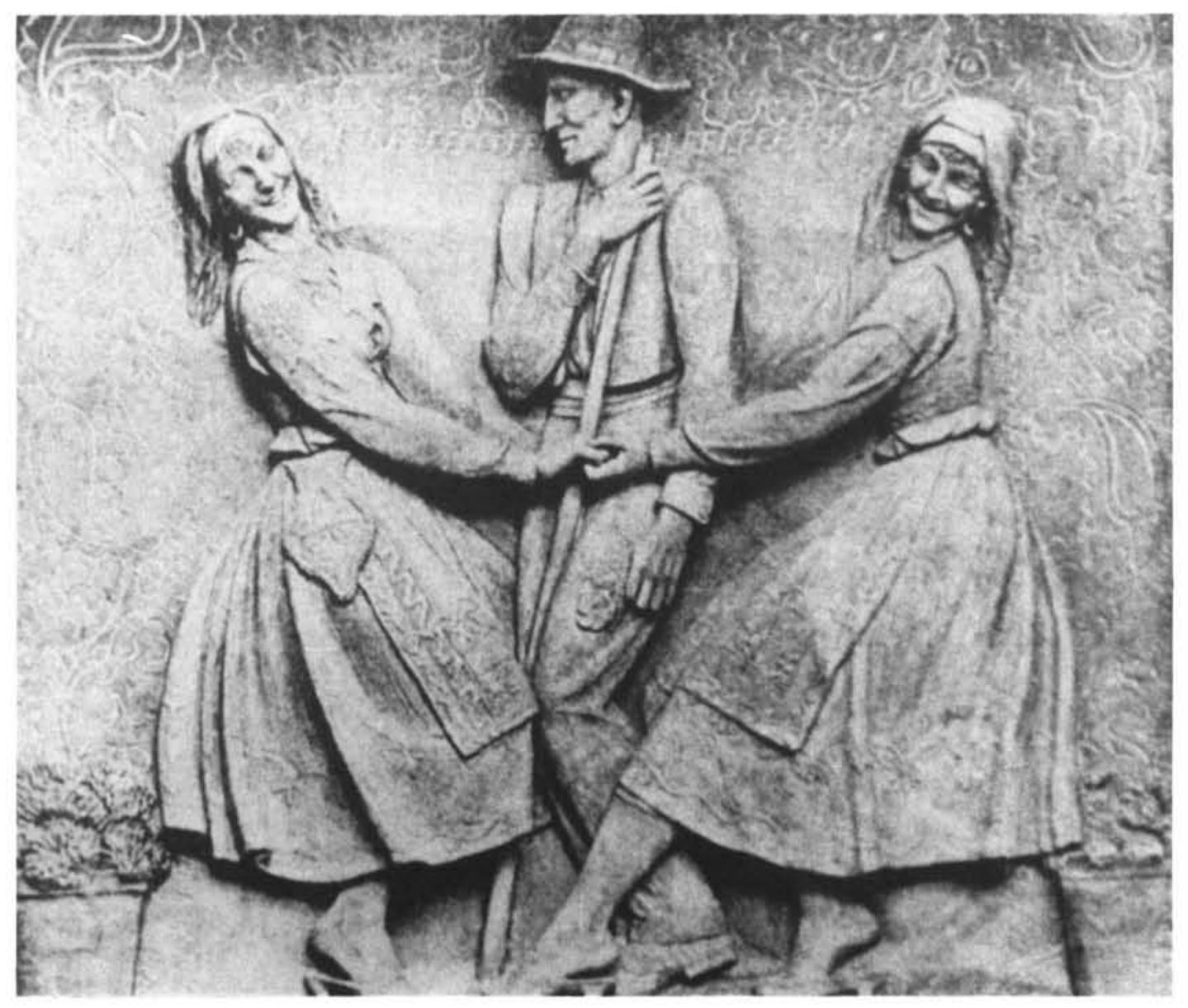

Fig. 6. 


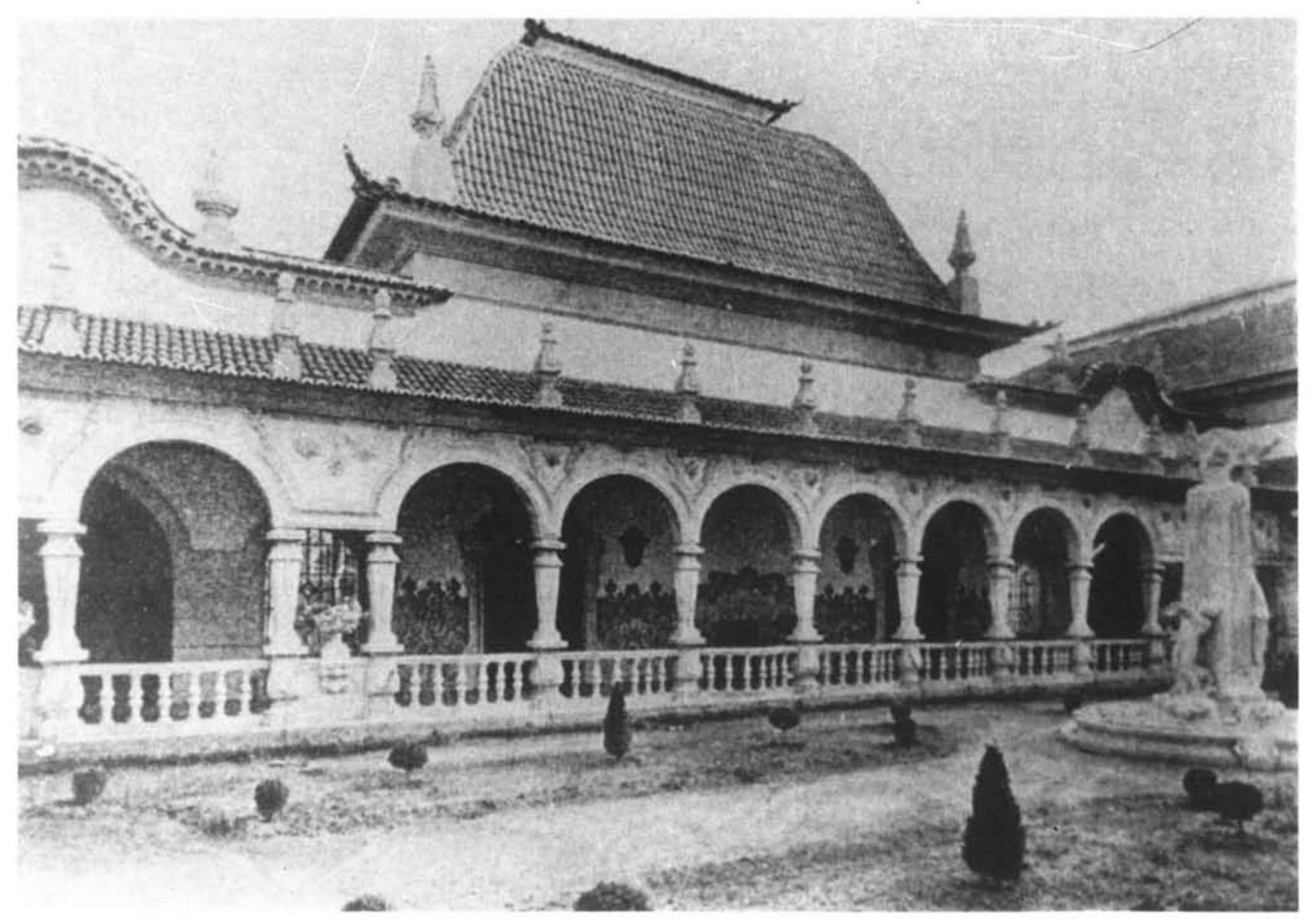

Fig. 7.

Patio principal del pabellón, con la Fuente de la Juventud, obra de João da Silva. 


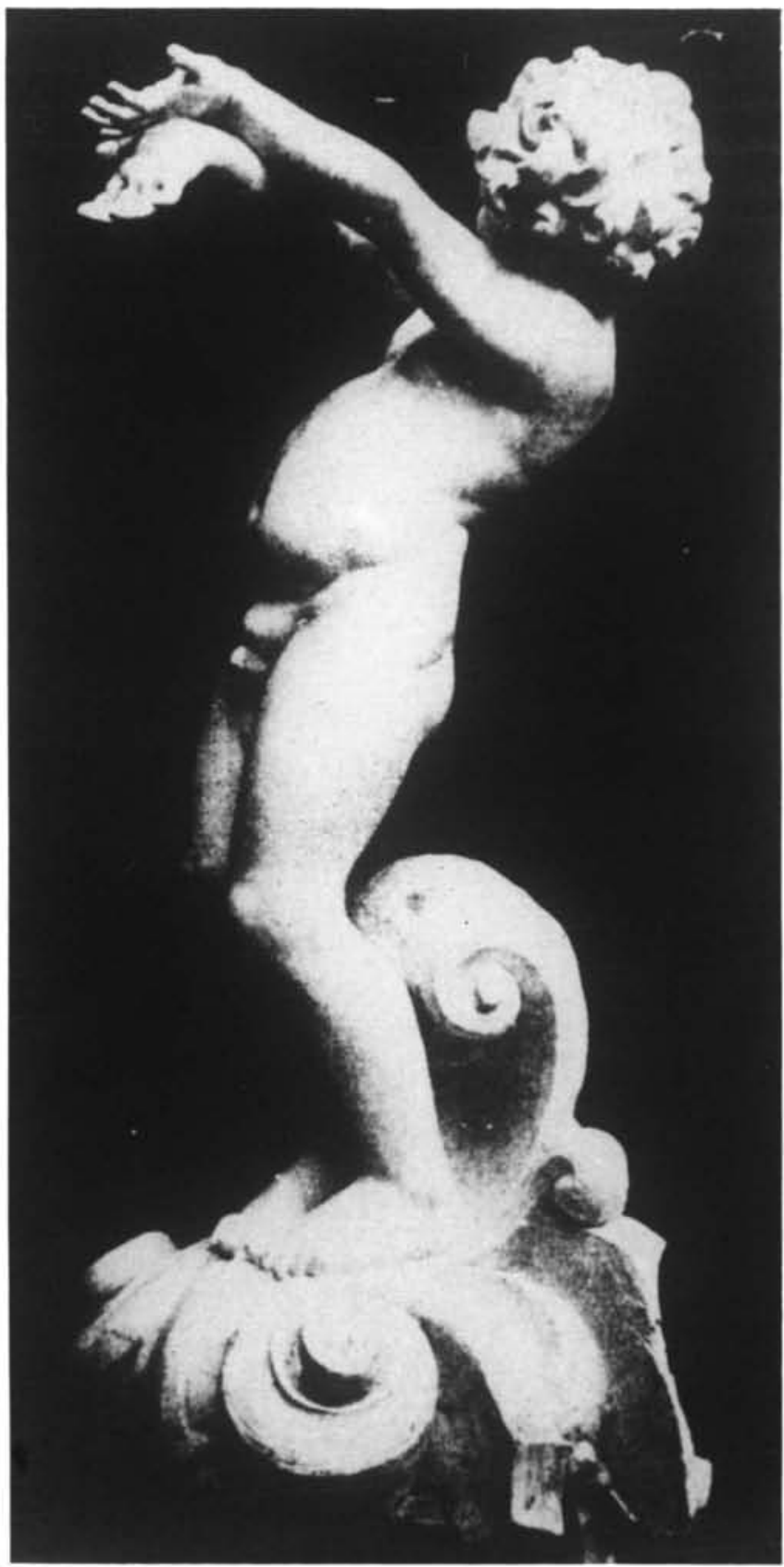

Fig. 8.

Detalle de la anterior. Figura de niño (JOAO DA SILVA, en Ilustraçao Moderna de Porto, abril de 1929 , núm. 32 año 4 ). 